\title{
Can education quality be statistically measured?
}

\author{
Ekaterina Bagrova*, and Sergei Kruchinin \\ Industrial University of Tyumen, Severnay st., 46, Noyabrsk, Russia
}

\begin{abstract}
Currently there are many theories about quality education. The paper presents some of them. It also includes some points of Deming's philosophy and statistical indicators implemented to determine lecturers' achievements in Russian higher education. The paper shows that these indicators do not align with Deming's quality goals, according to both educational and quality theories. A new system of measurements should thus be developed. This system should be based upon ideas about the definition of a quality education, not only on personal achievements of instructors and lecturers.
\end{abstract}

\section{Introduction}

Statistical assessment and control are the foundations of a modern understanding of the world and quality. The field of education has not been left out. We can say that education is more and more often measured statistically. The Ministry of education introduces criteria for the quality of educational programs, directions, and even teachers in statistically measurable indicators. The main goal of this article is to understand whether it is possible to measure the quality of education in numbers, and how this approach is appropriate in the modern world? Does it lead to the formation of the quality of education?

\section{Methods}

In this study, the issue of statistical measurement of education quality is analysed. For this analysis, three aspects are discussed: defining the quality of education; quality principles that can be applied to the quality of education; and current Russian statistical measurements of educational quality [1]. The study provides insight into whether these measurements match quality of education principles and quality theory [2].

\section{Results}

The quality of education is defined here as the relevance and application of acquired knowledge in specific conditions to achieve a specific goal and improve the quality of life.

\footnotetext{
* Corresponding author: bagrova.e.v@mail.ru
} 
The quality of knowledge is determined by its fundamental nature, depth and relevance in work after graduation [3].

\subsection{Components of education quality and their relationship}

If we define the quality of education such that the quality of the result is the primary factor, then the quality of the educational process and conditions are deemed as secondary. To determine the quality of education, many researchers study the quality of results, choosing from its components those that are optimal to specific educational institutions. Others approach the quality of education in its broader sense, which includes not only the quality of results, but also the process and conditions, although it is much more difficult to distinguish these three components [4]. Despite this, the main components affecting educational quality can be identified and studied to a great extent, even though the dynamic nature of each component makes it difficult to clearly separate one component from another.

The dynamic quality of education is due to the changing requirements of society, the labour market, and consumer education; that is, the process itself may change depending on these conditions. In this regard, and because of the structure and interconnectedness of the education quality system, it is preferable to consider education quality in a different way (Fig.1).

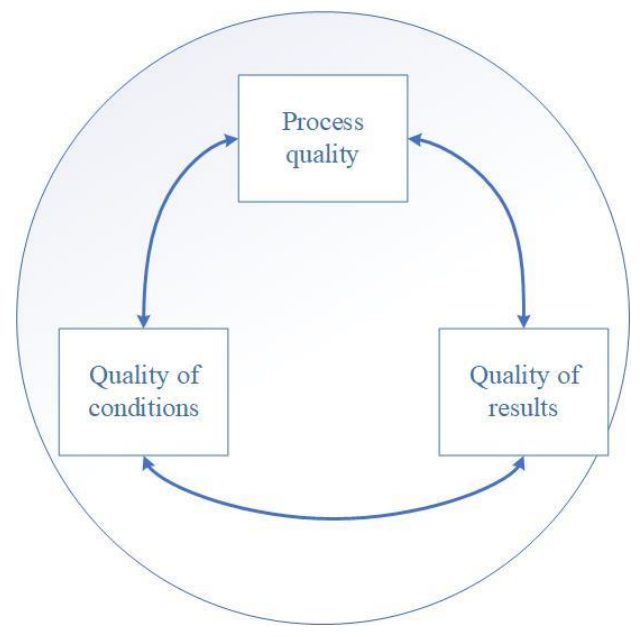

Fig. 1. Components of education quality

\subsection{Quality of education measures}

Based on the approach to understanding the quality of education, the following factors of quality indicators can be distinguished [5].

- Quality of teaching staff;

- State of the material and technical base of the educational institution;

- Motivation of the teaching staff;

- Quality of training programs;

- Quality of the students;

- Quality of infrastructure;

- Quality of knowledge;

- Innovation activity management; 
- Introduction of process innovations;

- Demand for graduates;

- Competitiveness of graduates in the labour market;

- Achievements of graduates.

\subsubsection{Teacher}

The main question for quality purposes is how to determine the quality of the teacher. The answer to this determines the content of education, the quality of educational programs, teaching methods, the competitiveness of graduates in the labour market, and other components of educational quality. At the same time, the teacher not only transmits knowledge, but also forms the personalities of the students, their worldview and spirituality. Therefore, the quality of a teacher is a complex concept that includes [6]:

- competence level ;

- ability to engage in teaching activities;

- observation - the ability to notice significant, characteristic features of students;

- ability to establish contacts with the external and internal environment;

- reputation;

- research activity;

- availability of a scientific school.

\subsubsection{Open education}

In open education, one of the features of which is distance, i.e. the presence of distance between the student and the educational institution, the tasks of the teacher change. The teacher coordinates the educational process, advises, manages educational projects, improves training courses, and improves their own skills. The educational process is becoming high-tech, incorporating the achievements of information and telecommunications technologies.

Each of the components of "teacher quality" can be detailed and, as a rule, cannot be quantified. For example, the level of competence is determined by basic education; subsequent self-education; the presence of an academic degree and title; experience in teaching; and practical experience in a particular field.

The quality of education depends on the motivation of the staff. Teachers should have an appropriate social status (i.e., respect in society) to ensure the attractiveness of teaching.

The quality of educational programs is manifested not only in compliance with educational standards in the field of a particular discipline, but also in the presence of an innovative component.

\subsubsection{Consumers}

At the centre of the educational process is the consumer of knowledge - the student. It is for students that lectures are given, textbooks are written, and new educational technologies are developed. Therefore, it is reasonable to discuss the quality of the student, which is the "material" that is transformed into the final result of the educational process.

The quality of knowledge is determined by its fundamental nature, depth and relevance to work after graduation. In open education, managers of regional centres can organize monitoring of graduates' careers, for which it is advisable to create databases on graduates. Since the majority of indicators of educational quality may not have quantitative 
characteristics, it is possible to obtain summary measures of the quality of the indicator blocks and a synthesis of these estimates with the help of quality control.

\subsubsection{Key points}

The quality of education can be considered as a multidimensional concept. It is advisable to approach the analysis of this concept from a process approach standpoint. This view is incorporated into the development of a quality management system to increase customer satisfaction by meeting their needs.

The quality of education is the demand for acquired knowledge, to be applied to specific conditions and places in order to achieve a specific goal and improve the quality of life.

The process approach includes the continuity of management; the sequence and interrelation of individual processes within the educational system, and their combination and interaction.

The quality management system is integrated, focused on modern information technologies, and utilises the achievements of management theory and practice. Its success can be assessed using qualitative and quantitative indicators.

\subsection{Deming's approach}

Deming is a renowned researcher in the field of quality management, who postulated several points. In this paper, a subset of them are covered [7].

1. Each company should use statistical methods for its management. All purposes must be measurable and explainable by particular actions. For example, a rise in productivity can be obtained through the reduction of defective product output.

2. Managers must provide clear goals to their staff instead of popular slogans.

3. Managers should lead and inspire by doing. They should not manage the staff by objectives.

Thus, some of these points include obvious contradictions. Managers have to achieve measurable purposes and, simultaneously, not manage staff by objectives. This is an extremely difficult balance.

\subsubsection{Current principles in Russia}

Currently, lecturers in Russian universities work under specific, measurable conditions. These may be separated into two categories: necessary and additional conditions. In table 1, examples of necessary conditions are presented.

Table 1. Necessary criterion

\begin{tabular}{|c|c|c|c|c|}
\hline Criteria & Professor & $\begin{array}{c}\text { Associate } \\
\text { professor }\end{array}$ & $\begin{array}{c}\text { Senior } \\
\text { lecturer }\end{array}$ & $\begin{array}{c}\text { Associate } \\
\text { lecturer }\end{array}$ \\
\hline $\begin{array}{c}\text { International publication } \\
\text { (Scopus, Web of Science) }\end{array}$ & 2 & 1 & 1 & 1 \\
\hline International conference & 1 & - & - & - \\
\hline Ph.D. students & 3 & - & - & - \\
\hline Ph.D. students' graduation & 1 & - & - & - \\
\hline $\begin{array}{c}\text { Local conference } \\
\text { realization }\end{array}$ & 1 & - & 6 & 6 \\
\hline $\begin{array}{c}\text { Participation in university } \\
\text { events }\end{array}$ & 6 & 6 & &
\end{tabular}


Table 1. Continued

\begin{tabular}{|c|c|c|c|c|}
\hline $\begin{array}{c}\text { Student's victories in } \\
\text { different competitions }\end{array}$ & - & 3 & 3 & 3 \\
\hline Books publishing & - & 2 & - & - \\
\hline
\end{tabular}

All lecturers must take part in university events at least 6 times per year. Moreover, each lecturer, excluding professors, must train at least 3 students and win some student competitions. This is made possible by special student events designed to earn their lecturers their achievements.

Moreover, there are different requirements for different types of lecturers; all of these requirements are very strict. There is no leadership at all, just these strong objectives. The necessary criteria for one lecturer are different for others. This situation motivates lecturers to achieve formal indicators instead of improving educational quality.

\section{Discussion and conclusion}

There are plenty of measurable indicators that characterize the quality of education in Russia. However, current indicators and criteria are far from actual quality, according to Deming's principles and others discussed above. The main issue is that current indicators are very formal and do not reflect true educational processes [2]. They specifically focus on scientific achievements of the lecturers and of their best students, without addressing regular students and their benefits [1]. As a result, it may be concluded that current measures are very far from reliable educational quality measurements. Thus, another system of measures should be developed. This system should be based on ideas about what defines the quality of education, not just on personal achievements of lecturers and their best students.

\section{References}

1. H. Irmayani, D. Wardiah, M. Kristiawan, International Journal of Scientific \& Technology Research, 7, 113 (2018)

2. A.Y. Noaman, A.H. Ragab, A.I. Madbouly, A.M. Khedra, A.G. Fayoumi, Studies in Higher Education, 42(1), 23 (2017)

3. K.G. Erdyneeva, et al., International Review of Management and Marketing, 6, (2016)

4. R.A. Madani, Higher Education Studies, 9, 100 (2019)

5. R.A. Cohen, et al., American Journal of Kidney Diseases, 68, 203 (2016)

6. F. Gajardo, N. Grau, International Journal of Educational Development, 65, 123 (2019)

7. M. Arian, et al., Quarterly Journal of Nursing Management, 4, 45 (2016)

8. W.E. Deming, MIT press (2018) 